\title{
Syringomyelia Associated with a Huge Retrocerebellar Arachnoid Cyst: A Case Report
}

\author{
Sung Baek Hue, Han Yu Seong, Soon Chan Kwon, In Uk Lyo, Hong Bo Sim \\ Department of Neurosurgery, Ulsan University Hospital, University of Ulsan College of Medicine, Ulsan, Korea
}

Occasionally, a posterior fossa arachnoid cyst can induce compression of the spinal cord and cause syringomyelia. Here, we report the case of a 29-year-old man with both progressive shoulder pain and gait disturbance, who was found to have a huge retrocerebellar arachnoid cyst associated with syringomyelia. Accordingly, posterior fossa decompression and arachnoid cyst excision were performed. Post-operative MRI showed a marked reduction in the size of the arachnoid cyst and syringomyelia. The patient's symptoms were clearly improved compared to before surgery. In our view, treatment in such patients should focus on decompressing the foramen magnum and include the removal of the coexistent arachnoid cyst walls, which appear to be the crucial factor in development of syringomyelia. In this report, we discuss the pathogenic mechanisms underlying syringomyelia-associated retrocerebellar arachnoid cyst and review the current literature on this topic.

Key Words: Posterior fossa $\cdot$ Arachnoid cyst $\cdot$ Syringomyelia

\section{INTRODUCTION}

Syringomyelia is associated with many intracranial and spinal anomalies. The association of posterior fossa lesions with syringomyelia has been described occasionally both for solid and cystic pathologies ${ }^{4,14)}$. Few cystic lesions of posterior fossa have been found in association with syringomyelia, and even fewer have been reported in the huge retrocerebellar arachnoid cysts associated with syringomyelia ${ }^{9,18)}$. In the majority of these cases, development of syringomyelia was related to obstruction of cerebrospinal fluid (CSF) flow caused by a downward invagination of the cyst itself or tonsillar decent within the foramen magnum ${ }^{11,13)}$. The clinical features of syringomyelia are highly variable, usually with an insidious onset, a course that lasts for many years, and an unpredictable pace of progression ${ }^{19)}$. Multiple treatment options for retrocerebellar arachnoid cysts have been introduced including cyst fenestration, cyst-peritoneal shunting, and foramen magnum

\footnotetext{
- Received: June 19, 2015 - Revised: August 26, 2015

- Accepted: September 4, 2015

Corresponding Author: Han Yu Seong, MD, PhD

Department of Neurological Surgery, Ulsan University Hospital, University of Ulsan College of Medicine, 877, Bangeojinsunhwando-ro, Dong-gu, Ulsan 44033, Korea

Tel: +82-52-250-7139, Fax: +82-52-250-7138

E-mail: drhanyu@naver.com

$\otimes$ This is an Open Access article distributed under the terms of the Creative Commons Attribution Non-Commercial License (http://creativecommons.org/ licenses/by-nc/3.0/) which permits unrestricted non-commercial use, distribution, and reproduction in any medium, provided the original work is properly cited.
}

decompression with complete or partial excision ${ }^{1,4,15)}$. We describe the case of a patient with a huge retrocerebellar cyst associated with CSF flow impairment in the foramen magnum and the resulting in syringomyelia.

\section{CASE REPORT}

A 29-year-old man was brought into the clinic following a complaint of dizziness, gait disturbance, and shock-like pain occurring in both shoulders over the course of several months. Upon neurological examination, the patient was fully conscious, and functioning of the cranial nerve was within the normal range. Motor power was preserved in all four limbs, but paresthesia on the left side of the upper limb was noted. Deep tendon reflexes were increased and abnormal reflexes (e.g., Hoffman sign, ankle clonus) were present. The rest of the examination was unremarkable. Magnetic resonance imaging (MRI) showed a large cystic mass at the posterior fossa with compression of the $4^{\text {th }}$ ventricle and the brain stem with extension into the foramen magnum, which resulted in syringom- yelia occurring from $\mathrm{C} 1$ to $\mathrm{T} 10$ and a mild dilatation of the lateral and the $3^{\text {rd }}$ ventricle (Fig. 1A). Cine MRI revealed that the flow of CSF was present below only the foramen magnum (Fig. 2A). The patient underwent a suboccipital craniotomy and $\mathrm{C} 1$ laminectomy with the removal of the arachnoid cyst's walls. The dura mater was closed with a dural graft. Histopathological analysis of the excised tissues showed flattening of meningothelial cells attached to a loose fibrous wall with normal 

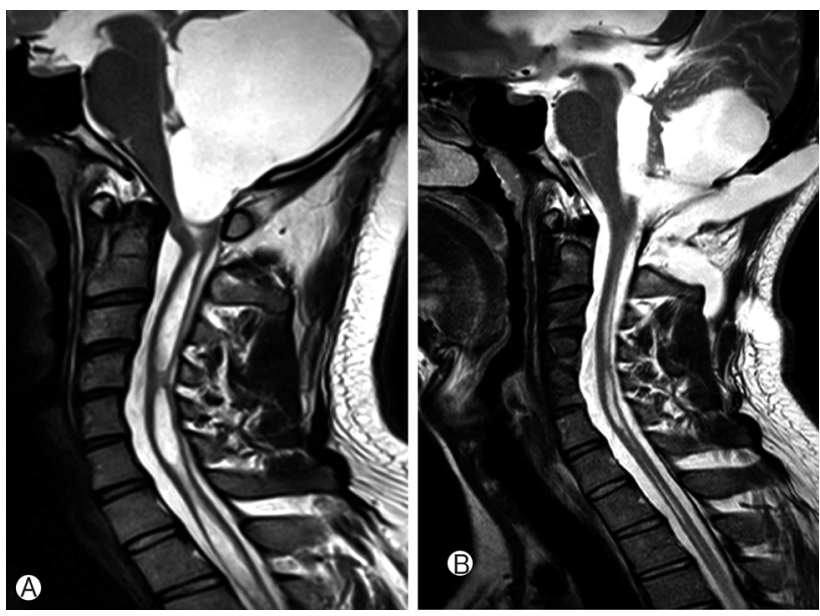

Fig. 1. (A) Magnetic resonance imaging (MRI) revealed a large cystic mass at the posterior fossa with compression of the $4^{\text {th }}$ ventricle and the brain stem with extension to the foramen magnum, resulting in syringomyelia from $\mathrm{Cl}$ to $\mathrm{T1O}$ and mild dilatation of the lateral and $3^{\text {rd }}$ ventricles. (B) On postoperative MRI, a residual cyst was noted but the size and extent of syringomyelia was decreased.
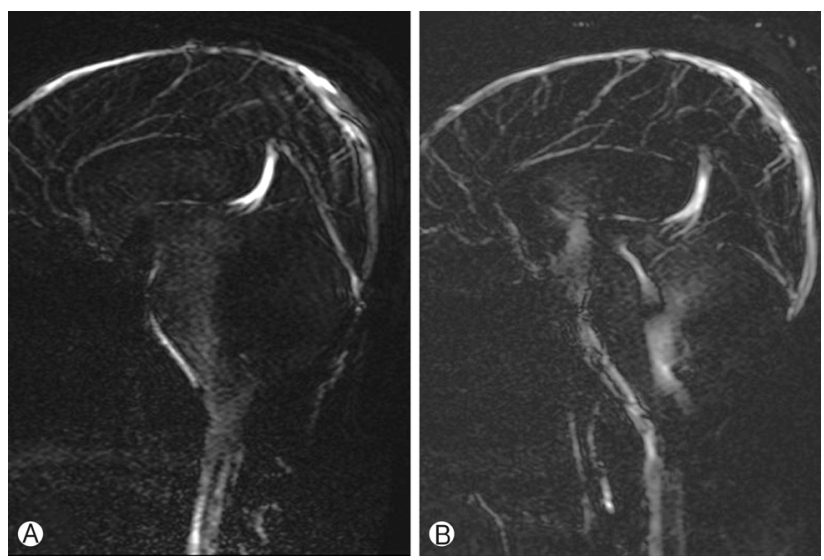

Fig. 2. An image showing CSF flow at the aqueduct of Sylvius, lateral, $3^{\text {rd }}$ and $4^{\text {th }}$ ventricles as well as CSF flow passing from the interpeduncular cistern to the foramen magnum. The improvements to CSF flow are showing on postoperative Cine MRI (A) as compared to preoperative one (B).

vessels (Fig. 3). Postoperative MRI revealed a residual cyst, but the size and extent of syringomyelia had decreased (Fig. 1B). In addition, CSF flow was improved on cine MRI (Fig. 2B) and clinically, the patient's symptoms were marke- dly improved.

\section{DISCUSSION}

Arachnoid cysts are benign intra-arachnoid fluid collections that develop as the result of an abnormal duplication of the

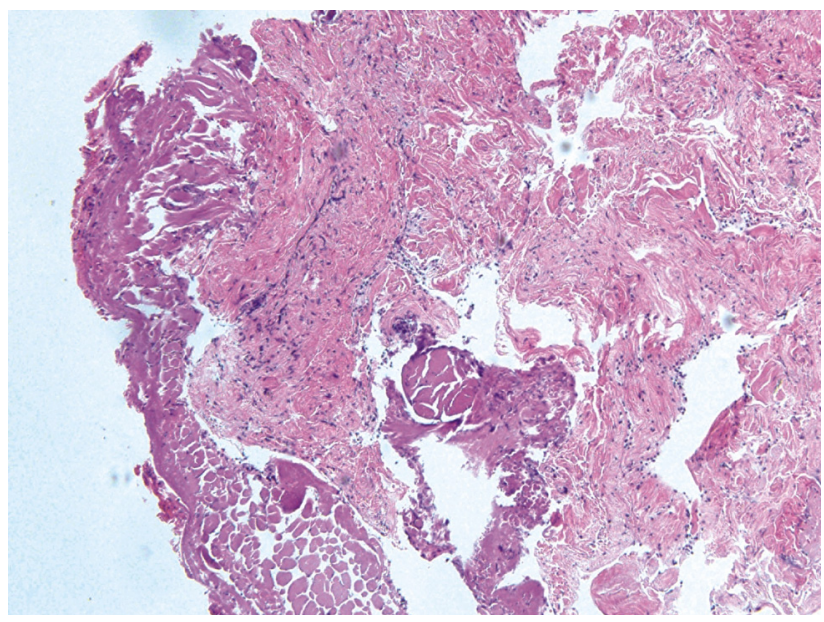

Fig. 3. Pathological findings. Hematoxylin and eosin staining showed fibrous tissue on the wall of the cyst, and no epithelial cells were observed; the patient was diagnosed with arachnoid cyst $(\times 200)$.

arachnoid membranes during brain development. In patients with arachnoid cysts, neurological signs and symptoms reflect cyst size, anatomic distribution, and its impact on CSF flow. Arachnoid cysts account for approximately $1 \%$ of all intracranial mass lesions ${ }^{3}$. Posterior fossa arachnoid cysts represent roughly one fourth of all these congenital pouches. There have been several other reports that have noted large arachnoid cysts associated with syringomyelia ${ }^{9,18)}$.

Syringomyelia is associated with many intracranial and spinal anomalies ${ }^{5}$. One study postulated that syringomyelia results from obstruction of CSF flow at the foramen magnum and the outlet of the fourth ventricle ${ }^{2)}$. Obstruction of CSF flow may lead to an increased pulsatile pressure within the spinal canal and forcing CSF into the spinal cord ${ }^{177}$. Most posterior fossa arachnoid cysts result in cerebellar tonsillar herniation, consequently leading to compression of the spinal cord and syringomyelia resulting from the presence of the mass. The socalled "acquired" Chiari malformation (CM) seems to be better understood. Oldfield et al. ${ }^{16)}$ propose that the descended tonsils obstruct the CSF flow to and from the spinal compartment at the foramen magnum thus explaining the appearance of syringomyelia.

However, as in our case it is extremely rare for a huge retrocerebellar arachnoid cyst at the foramen magnum to directly compress the spinal cord and result in syringomyelia. MartinezLage et al. ${ }^{12)}$ identified 15 published cases of syringo- myelia accompanying diverse cystic processes of the posterior fossa, such as congenital arachnoid cysts, Dandy-Walker malformation, Blake's pouch cyst, and posttraumatic CSF pouches. In 14 of those cases, the obstruction of normal CSF flow through the foramen magnum was due to blockage by the walls of the cyst itself. In all these cases, there was a coexistent syringo- 
myelia. Jain et al. ${ }^{8)}$ documented one case of a giant posterior fossa arachnoid cyst extending into and compressing the spinal cord and resulting in syringomyelia. Kiran et al. ${ }^{10)}$ also reported such a case.

Many patients with large posterior fossa lesions may have associated syringomyelia but no symptoms related to the syringomyelia. Thus, it is important to image the entire length of spine in all the patients presenting with posterior fossa mass lesions. Clinical manifestations of CM-1 malformation and syringomyelia associated with posterior fossa arachnoid cysts involved in foramen magnum obstruction are head and neck pain, retroocular pain, cerebellar signs, cranial nerve dysfunction, sleep apnea, and respiratory difficulty. Furthermore, patients presenting with spinal cord compression may show a loss of fine movements, dysesthesia, dissociated sensory loss, sensory level, spasticity, scoliosis, or sphincter disturbances ${ }^{6}$.

Various surgical options exist for the treatment of retrocerebellar arachnoid cyst according to the underlying pathogenic mechanism, including cyst fenestration, cyst-peritoneal shunting, and foramen magnum decompression with complete or partial excision ${ }^{1,415)}$. Removal of the underlying pathology and stablishing the normal CSF flow at the foramen magnum is the main stay of treatment for syringomyelia ${ }^{9)}$. For cases of foramen magnum arachnoid cyst with direct compression of the spinal cord and syringomyelia, excision should be performed as much as possible with complete decompression of the posterior fossa, which should result in a satisfying outcome even if the arachnoid cyst is unable to be completely excised ${ }^{\text {t }}$.

We report here a case of patient who received decompression of the posterior fossa with a partial cyst excision, which markedly improved his symptoms. Even though the post-ope rative MRI showed a residual cyst, there was a reduction in the syrinx size. We feel that the surgical management of a huge retrocerebellar arachnoid cyst itself is attributed to syringomyelia, fenestration of the cyst and expansion of the fora men magnum, leading to restoration of the CSF pathway. In addition, suboccipital craniotomy, with open cyst removal, offers the opportunity to explore the lesions and to relieve any arachnoid adhesions that may further restrict CSF flow.

\section{CONCLUSION}

We present a case report of a huge retrocerebellar arachnoid cyst with syringomyelia. Our patient's symptoms markedly improved after suboccipital craniotomy and C1 laminectomy with the partial removal of the arachnoid cyst's walls. We briefly reviewed previous cases of syringomyelia associated with posterior fossa cysts. In this as in other types of posterior fossa lesions associated with syringomyelia, we recommend that the surgical management be used to address underlying hypothetical mechanism.

\section{REFERENCES}

1. Apok V, Constantini S, Roth J: Microsurgical fenestration of retrocerebellar cysts as a treatment for syringomyelia. Childs Nerv Syst 28:653-656, 2012

2. Arunkumar MJ, Korah I, Chandy MJ: Dynamic CSF flow study in the pathophysiology of syringomyelia associated with arachnoid cysts of the posterior fossa. Br J Neurosurg 12:33-36, 1998

3. Cincu R, Agrawal A, Eiras J: Intracranial arachnoid cysts: current concepts and treatment alternatives. Clin Neurol Neurosurg 109:837-843, 2007

4. D'Osvaldo DH, Otero JM, Mosconi JB, Oviedo JD: Regression of symptomatic syringomyelia after resection of posterior fossa tumour. Acta Neurochir (Wien) 144:385-388, 2002

5. Doughty KE, Tubbs RS, Webb D, Oakes WJ: Delayed resolution of Chiari I-associated hydromyelia after posterior fossa decompression: case report and review of the literature. Neurosurgery 55:711, 2004

6. Galarza M, Lopez-Guerrero AL, Martinez-Lage JF: Posterior fossa arachnoid cysts and cerebellar tonsillar descent: short review. Neurosurg Rev 33:305-314, 2010

7. Huang H, Li Y, Xu K, Li Y, Qu L, Yu J: Foramen magnum arachnoid cyst induces compression of the spinal cord and syringomyelia: case report and literature review. Int J Med Sci 8: 345-350, 2011

8. Jain R, Sawlani V, Phadke R, Kumar R: Retrocerebellar arachnoid cyst with syringomyelia: a case report. Neurol India 48:8183, 2000

9. Joshi VP, Valsangkar A, Nivargi S, Vora N, Dekhne A, Agrawal A: Giant posterior fossa arachnoid cyst causing tonsillar herniation and cervical syringomyelia. J Craniovertebr Junction Spine 4:43-45, 2013

10. Kiran NA, Kasliwal MK, Suri A, Mahapatra AK: Giant posterior fossa arachnoid cyst associated with syringomyelia. Clin Neurol Neurosurg 112:454-455, 2010

11. Marin-Padilla M, Marin-Padilla TM: Morphogenesis of experimentally induced Arnold--Chiari malformation. J Neurol Sci 50: 29-55, 1981

12. Martinez-Lage JF, Almagro MJ, Ros de San Pedro J, Ruiz-Espejo A, Felipe-Murcia M: Regression of syringomyelia and tonsillar herniation after posterior fossa arachnoid cyst excision. Case report and literature review. Neurocirugia (Astur) 18:227-231, 2007

13. Martinez-Lage JF, Ruiz-Espejo A, Guillen-Navarro E, Almagro MJ: Posterior fossa arachnoid cyst, tonsillar herniation, and syringomyelia in trichorhinophalangeal syndrome Type I. J Neurosurg 109:746-750, 2008

14. Muzumdar D, Ventureyra EC: Tonsillar herniation and cervical syringomyelia in association with posterior fossa tumors in children: a case-based update. Childs Nerv Syst 22:454-459, 2006

15. Nomura S, Akimura T, Imoto H, Nishizaki T, Suzuki M: Endoscopic fenestration of posterior fossa arachnoid cyst for the treatment of presyrinx myelopathy- case report. Neurol Med Chir 
(Tokyo) 42:452-454, 2002

16. Oldfield EH, Muraszko K, Shawker TH, Patronas NJ: Pathophysiology of syringomyelia associated with Chiari I malformation of the cerebellar tonsils. Implications for diagnosis and treatment. J Neurosurg 80:3-15, 1994

17. Pinna G, Alessandrini F, Alfieri A, Rossi M, Bricolo A: Cerebrospinal fluid flow dynamics study in Chiari I malformation: im- plications for syrinx formation. Neurosurg Focus 8:E3, 2000

18. Shinoda S, Tanaka K, Kawaguchi K: A huge retrocerebellar arachnoid cyst with syringomyelia: case report. No Shinkei Geka 26:363-367, 1998

19. Zager EL, Ojemann RG, Poletti CE: Acute presentations of syringomyelia. Report of three cases. J Neurosurg 72:133-138, 1990 